Severe intimate partner violence affecting both young and elderly patients of both sexes

Hackenberg, E. A. M.

2017-06

Hackenberg, E A M , Sallinen , V , Koljonen , V \& Handolin , L 2017 , ' Severe intimate partner violence affecting both young and elderly patients of both sexes ' , European Journal of Trauma and Emergency Surgery , vol. 43 , no. 3 , pp. 319-327 . https://doi.org/10.1007/s00068-016-0646-9

http://hdl.handle.net/10138/237058

https://doi.org/10.1007/s00068-016-0646-9

unspecified

publishedVersion

Downloaded from Helda, University of Helsinki institutional repository.

This is an electronic reprint of the original article.

This reprint may differ from the original in pagination and typographic detail.

Please cite the original version. 


\title{
Severe intimate partner violence affecting both young and elderly patients of both sexes
}

\author{
E.A.M Hackenberg ${ }^{1,2} \cdot$ V. Sallinen ${ }^{3} \cdot$ V. Koljonen ${ }^{4} \cdot$ L. Handolin $^{1}$
}

Received: 16 November 2015 / Accepted: 1 February 2016 / Published online: 2 March 2016

(C) Springer-Verlag Berlin Heidelberg 2016

\begin{abstract}
Background Intimate partner violence (IPV) affects $25-35 \%$ of women and men in Western countries. Despite the high prevalence of IPV among trauma patients, very little is known about the associated injuries. Most previous studies excluded male victims and IPV is often limited to violence against women. Few reports on IPV among elderly patients exist.

Methods We examined self-reports of IPV among patients at two major trauma centers of the Helsinki Central Hospital in Finland. Based on previous studies, we hypothesized that we would find the most severe injuries among young and middle-aged women.
\end{abstract}

Electronic supplementary material The online version of this article (doi:10.1007/s00068-016-0646-9) contains supplementary material, which is available to authorized users.

\section{E.A.M Hackenberg}

elisa.hackenberg@hus.fi

V. Sallinen

ville.sallinen@helsinki.fi

V. Koljonen

virve.koljonen@hus.fi

L. Handolin

lauri.handolin@hus.fi

1 Department of Orthopedics and Traumatology, Helsinki University Hospital, University of Helsinki, Helsinki, Finland

2 Department of Surgery, South Karelian Central Hospital, Lappeenranta, Finland

3 Department of Abdominal Surgery, Helsinki University Hospital, University of Helsinki, Helsinki, Finland

4 Department of Plastic Surgery, Helsinki University Hospital, University of Helsinki, Helsinki, Finland
Results We identified 29 patients with a total of 105 injuries; patients typically presented with multiple injuries. Half of all patients required hospitalization or surgery. Contrary to previous studies, $17 \%$ of our cohort were male, while $17 \%$ of patients were 65 years or older. We found that $40 \%$ of male victims presented with a New Injury Severity Score (NISS) over 15, indicating severe trauma. Two elderly patients presented with an NISS of 27, the highest in our study.

Conclusions IPV leads to severe injury across all age groups among both male and female patients. The injury mechanism should be clearly defined for all trauma patients, keeping IPV in mind as a potential cause despite patient age or gender.

Keywords Intimate partner violence $\cdot$ Injury $\cdot$ Emergency room $\cdot$ Age $\cdot$ Gender $\cdot$ New Injury Severity Score

\section{Introduction}

Intimate partner violence (IPV) refers to physical, mental, or sexual abuse within an intimate relationship [1]. It is considered a major health problem globally affecting both women and men. Recent surveys found that 25-35\% of women in Europe and in the United States and $29 \%$ of men in the United States have experienced violence from an intimate partner during their lifetime [2, 3]. Hence, IPV represents a major cause of non-fatal injury among women in the United States [4]. Until recently, scholars considered only young and middle-aged women as potential IPV victims, whereby most studies on IPV-related injuries excluded male victims [5]. Few reports of IPV among elderly victims exist and IPV among older individuals is considered less severe than that experienced by younger 
individuals [6]. Alcohol and drug abuse are commonly associated with IPV in Western countries. Although causality is difficult to prove, violence often precedes abuse [7]. In the United States, IPV-related costs exceed an estimated $\$ 8.3$ billion annually. The health care cost per year on IPV victims results in $90 \%$ more spending per year than that for non-abused women $[8,9]$.

In addition to the immediate injuries due to physical violence, IPV carries numerous long-term adverse consequences on a victim's health including those which are potentially lethal. Globally, at least one in seven homicides are perpetrated by an intimate partner [10]. Previous reports describing the health sequelae related to IPV included chronic pain, functional gastro-intestinal disorders, cardiac symptoms, gynecological problems, sexually transmitted infections, and unintended pregnancies. The most common effects of IPV on mental health include depression, posttraumatic stress disorder, suicide attempts, insomnia, anxiety, and social dysfunction [11].

Although IPV often goes underreported and undiagnosed in health care settings, prevalence remains high among orthopedic trauma patients [12]. In a recent multinational prevalence study, $30 \%$ of female trauma patients presented with a history of IPV and 1 in 50 female patients presented in orthopedic emergency rooms specifically for IPV-related injuries. Still, only $6 \%$ such patients was ever asked about IPV by a health care professional [12].

This paper aims to examine patient profiles, injury patterns, and subsequent treatment for self-reporting IPV victims admitted to two large trauma centers from the Helsinki Central Hospital during a 12-month period. Based on previous studies, we hypothesized that the most severe injuries would occur among young and middle-aged female victims.

\section{Patients and methods}

We identified IPV victims admitted to the Helsinki University Central Hospital, to either Töölö Hospital (Helsinki University Hospital trauma unit) or Meilahti Hospital (Helsinki University Hospital emergency surgery unit), between August 20, 2013 and August 20, 2014. In our study, we included patients who reported an injury resulting from abuse by a current or previous partner. No screening for IPV victims was performed in either hospital, so only the self-reporting IPV victims were included in the study. Data on the victim's gender, age, relationship with the perpetrator, injuries, admission date, length of hospital stay, type of visit (inpatient or outpatient), and surgical treatment were collected from the hospital's electronic records. The New Injury Severity Score (NISS) was assessed for each patient [13].
The Töölö Hospital Emergency Department uses a structured form for all patients presenting as victims of violence to gather the patient history and document the abuse and injuries. This structured form takes its name from an abbreviation of the Finnish words for assault, battery and body map (hereafter referred to as "assault and body map" or ABM form (Fig. 1)). The ABM form consists of two pages of questions on the abuse and abuser, experienced violence, injuries, and social conditions such as the involvement of any children. The third page includes a body map, on which injuries are documented using specific symbols. Photographs of the injuries are included with the patient's permission. A nurse, in concert with a physician, completes the ABM form after a physical examination. Completion of the form takes less than $10 \mathrm{~min}$. The purpose of the ABM form is to document the violence for future legal purposes, as well as to serve as a mini-intervention [14].

The ABM form is not used at the Meilahti Hospital Emergency Department. We, therefore, included all patients with an ICD-10 diagnosis of S10-S99 and T00-T01, indicating the cause of the injury as non-self-inflicted violence. Clinical files were reviewed and patients self-reporting as IPV victims were included in our study.

We performed all statistical analyses using SPSS version 22 (IBM, Armonk, NY, USA). For the univariate analyses, we compared continuous variables using the Mann-Whitney $U$ test.

Categorical variables were analyzed for statistical significance using the Fisher's exact test. In all analyses, we performed two-sided hypothesis testing, where $p$ values $<0.05$ were considered significant.

The internal review boards from the Departments of Orthopedics and Traumatology and Abdominal Surgery, Helsinki University Central Hospital approved this study and its plan.

\section{Results}

\section{All patients}

We identified 29 patients who reported IPV as the cause of their injuries. In total, patients included $24(83 \%)$ women and $5(17 \%)$ men, with a median age of 41 years (range of 24-69 years). In 22 (76\%) cases, the abuser was male. Upon admission, $13(45 \%)$ patients were intoxicated and $9(31 \%)$ reported a history of substance abuse. A sharp weapon was used in $9(31 \%)$ cases, while $5(17 \%)$ patients were hit with a blunt object, typically a household item.

Supplemental Figure 1 illustrates the admissions of these 29 patients stratified by month. The staff in Töölö Hospital 


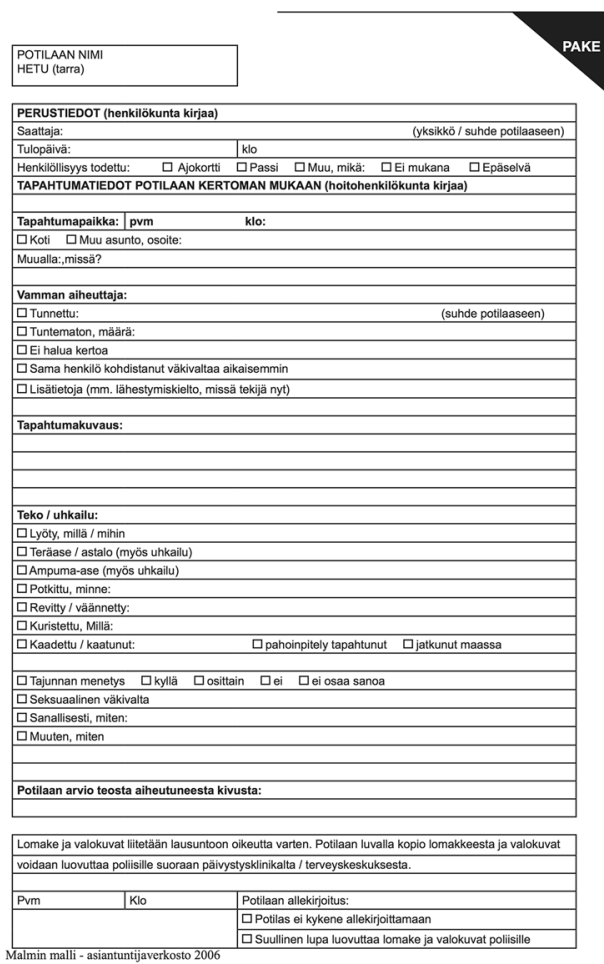

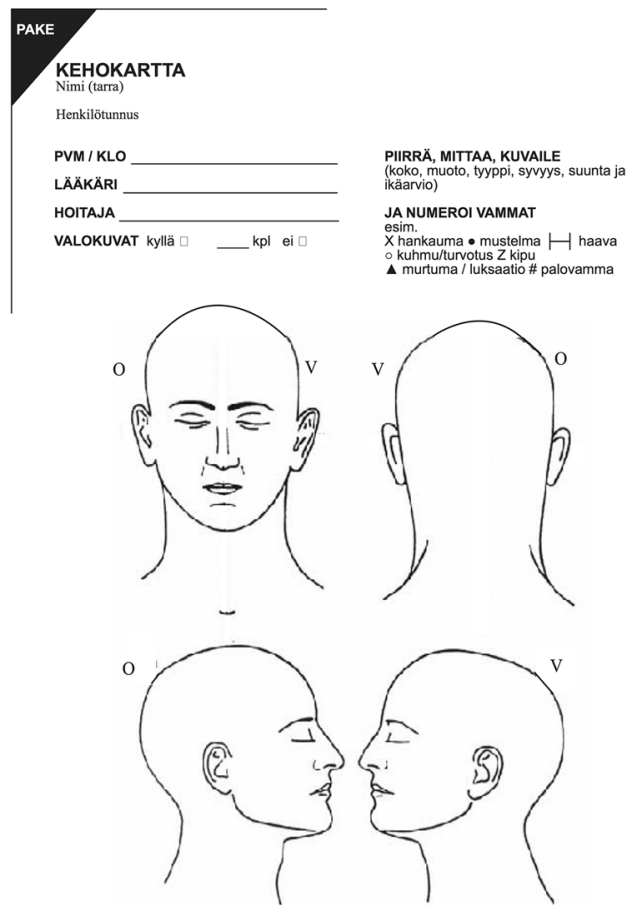

Malmin malli - asiantuntijaverkosto 2006

RokA, MITTAA, KUVALLE
oko, muoto, tyypi, sylyyss, suunta ja JA NUMEROI VAMMAT hankauma • mustelma $\longmapsto$ haava

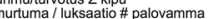

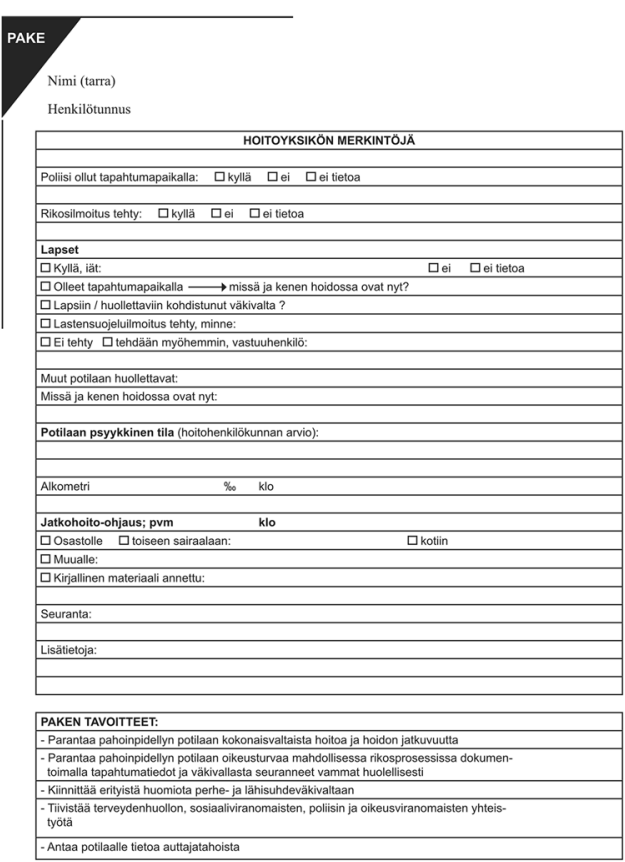

Melmin malli- asiantuntijijverkosto 2006

KEHOKARTTA
Nimi (tarra)
Henkilötunnus
PVM / KLO
LAAKÄRI
HOITAJA
VALOKUVAT Kyllä $\square \quad \_\quad k p l$ ei $\square$
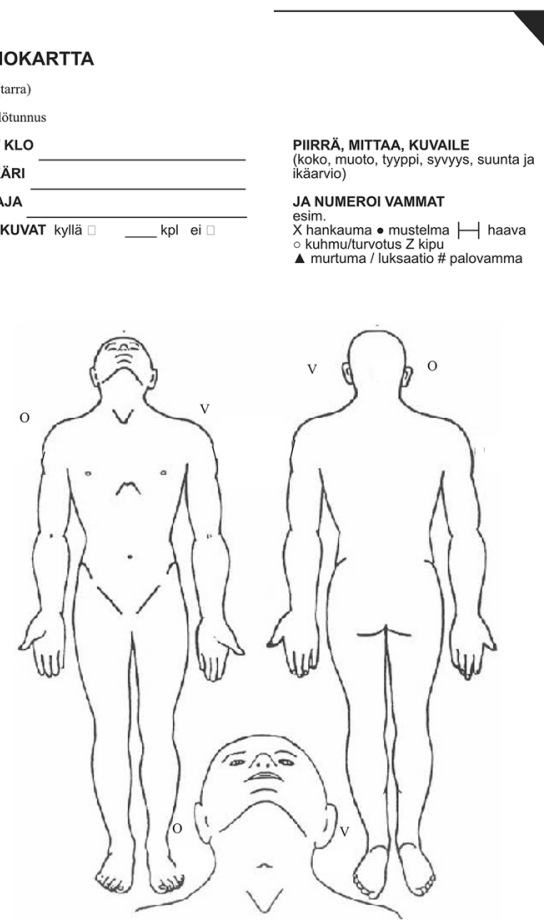

Malmin malli - asiantuntijiaverkosto 2006

Fig. 1 The Abuse and Body Map (ABM) form includes detailed information about the abuse, the violence and the injuries

was informed about the study in August 2012 and reminded a few times during the year (during October and February) year, which was noted as a peak in the incidence. None of the admissions happened around major holidays.
Our study sample included no deaths. However, patients typically presented with multiple injuries. The median number of injuries per patient stood at 3 (range of 1-10 injuries per patient), while the median NISS reached 3 
(range of 1-34). The most common injury sites included the upper limb (59\%), face (45\%), head (41\%), and the thorax $(34 \%)$.

In total, we recorded 105 injuries, whereby 30 bruises and 19 wounds represented the most common types of injuries. We also recorded 18 fractures among $12(60 \%)$ patients, typically facial, upper limb, and costal fractures. One of the seven intracranial injuries recorded, consisting of a bilateral subdural hematoma, cerebral contusion hematoma, and a suspected diffuse axonal injury, led to persistent neurological symptoms at a 3-month follow-up visit. The four penetrating thoracic injuries included one diaphragmatic stab and one heart stab (right atrium). Two patients were stabbed in the abdomen, leading to four intraabdominal injuries and two retroperitoneal injuries. These included one colic and one small intestine injury, one splenic injury, and one perinephric hematoma.

In total, 14 (48\%) patients were hospitalized, while the median length of stay stood at 0 days (range of 0-15 days). Ten (34\%) patients needed surgical treatment and two (7\%) were admitted to the intensive care unit (ICU) postoperatively. Four fractures were reduced and splinted, and three wounds were sutured in the emergency room. Seven (24\%) patients were not admitted to the hospital, but were discharged from the emergency room with no further follow-up appointments.

More detailed results are presented in Tables 1 and 2.

\section{Male patients}

Our study included five $(17 \%)$ male patients. Neither their median age (41 years) nor their medical histories differed from the female patients in our study. All male victims were intoxicated upon admission, all with a blood alcohol content of over $0.2 \%$ as measured in the emergency room. We found a significant difference in the number of female $(n=8$ or $33 \%)$ and male $(n=5$ or $100 \%)$ patients presenting while intoxicated $(p=0.01)$. We found no difference, however, when comparing the number of injuries between female and male victims [median of 2.5 (IQR $1-5.8)$ vs. 3 (2-7.5) injuries; $p=0.38$ ]; all male victims presented with more than one injury (range of 2-10 injuries). We found a similar result when comparing NISS between male and female patients. There was no significant difference between female and male patients in terms of NISS [median of 3 (IQR 1.5-5.8) vs. 3 (IQR 2.5-30.5) NISS, $p=0.32$ ]. Male patients presented with no fractures or intracranial injuries. Perhaps due to the small sample size, we found no significant difference between female $(n=12$ or $50 \%)$ ) and male $(n=0$ or $0 \%)$ patients with fractures $(p=0.06)$ and female $(n=7$ or $29 \%)$ and male $(n=0$ or $0 \%)$ patients with intracranial injuries $(p=0.30)$. All $(100 \%)$ male victims presented with wounds, from which four cases resulted from a weapon of some kind (80\%). Four $(80 \%)$ patients needed hospitalization, but one patient left the hospital against medical advice. Three patients needed emergency surgery and one patient needed ICU observation postoperatively.

Table 3 provides a more detailed comparison between male and female IPV patients.

\section{Elderly patients}

Five patients $(17 \%)$ were aged 65 years or older, including four women and one man. All (100\%) of our elderly patients were married to or living with their abuser, with two patients $(40 \%)$ reporting a previous history of abuse. As expected, we found a significant difference in the medical histories among younger patients $(n=10$ or $42 \%)$ ) compared to elderly patients ( $n=5$ or $100 \%$ ) reporting previous histories of somatic disease $(p=0.04)$. No psychiatric conditions were reported among elderly patients, although three elderly patients $(60 \%)$ presented with a history of substance abuse. We found no significant difference between those younger than 65 years and elderly patients and when comparing the number of injuries [median of 2.5 (IQR 1-5) vs. 3 (IQR 1.0-8.5) injuries per patient; $p=0.80$ ] and NISS [median of 3 (IQR 2-5) vs. 4 (IQR 2.5-27) NISS; $p=0.30]$. Three $(60 \%)$ elderly patients were hospitalized, with two $(40 \%)$ receiving treatment surgically and one $(20 \%)$ patient requiring ICU observation postoperatively.

Table 4 provides a more detailed comparison by patient age.

\section{Discussion}

In this study, we found injuries due to IPV among 29 patients, including both men and women and representing all age groups $[2,3]$. The small number of patients in this study was due to our chosen methodology; we included only patients who self-reported as victims of IPV. The true incidence of IPV is beyond a doubt larger. The majority of patients in his study were victims of an initial blunt trauma leading to musculoskeletal injuries, contusions, lacerations, or fractures, and typically presented with multiple injuries. Contrary to our hypothesis, severe injuries were found among both men and women and across all age groups. While $52 \%$ of victims did not require hospitalization, four (14\%) patients presented with an NISS over 15, indicative of a life-threatening injury.

The Helsinki University Central Hospital catchment area includes 600,000 inhabitants. In addition to serving as a secondary level hospital for the Helsinki metropolitan area, it also serves as a tertiary hospital for southern 
Table 1 Demographic characteristics

\begin{tabular}{|c|c|c|c|c|c|}
\hline & Total & Female & Male & Adults $^{\mathrm{a}}$ & Elderly \\
\hline$N(\%)$ & 29 & 24 & 5 & 24 & 5 \\
\hline Female & $24(83)$ & $24(100)$ & $0(0)$ & $20(83)$ & $4(80)$ \\
\hline Male & $5(17)$ & $0(0)$ & $5(100)$ & $4(17)$ & $1(20)$ \\
\hline Median age, years (range) & $41(24-69)$ & $42(24-67)$ & $41(31-69)$ & $39(24-59)$ & $66(65-69)$ \\
\hline \multicolumn{6}{|l|}{ Gender of the abuser (\%) } \\
\hline Male & $22(76)$ & $22(92)$ & $0(0)$ & $18(75)$ & $4(80)$ \\
\hline Female & $4(14)$ & $0(0)$ & $4(80)$ & $3(13)$ & $1(20)$ \\
\hline Unknown & $3(10)$ & $2(8)$ & $1(20)$ & $3(13)$ & $0(0)$ \\
\hline \multicolumn{6}{|l|}{ Relationship to abuser (\%) } \\
\hline Married/engaged & $12(41)$ & $9(38)$ & $3(60)$ & $10(42)$ & $2(40)$ \\
\hline Cohabitating & $9(31)$ & $8(33)$ & $1(20)$ & $6(25)$ & $3(60)$ \\
\hline Dating & $6(21)$ & $6(25)$ & $0(0)$ & $6(25)$ & $0(0)$ \\
\hline Former partner & $2(7)$ & $1(4)$ & $1(20)$ & $2(8)$ & $0(0)$ \\
\hline \multicolumn{6}{|l|}{ Medical history (\%) } \\
\hline Somatic disease & $15(52)$ & $10(42)$ & $5(100)$ & $10(42)$ & $5(100)$ \\
\hline Mental condition & $8(28)$ & $6(25)$ & $2(40)$ & $8(33)$ & $0(0)$ \\
\hline \multicolumn{6}{|l|}{ Substance abuse $(\%)$} \\
\hline Alcohol & $7(24)$ & $4(17)$ & $3(60)$ & $4(17)$ & $3(60)$ \\
\hline Drugs & $1(3)$ & $1(4)$ & $0(0)$ & $1(4)$ & $0(0)$ \\
\hline Prescription drugs & $1(3)$ & $1(4)$ & $0(0)$ & $1(4)$ & $0(0)$ \\
\hline Intoxicated on admission & 13 & $8(33)$ & $5(100)$ & $11(46)$ & $2(40)$ \\
\hline \multicolumn{6}{|l|}{ Location of injury (\%) } \\
\hline Upper limb & $17(59)$ & $14(58)$ & $3(60)$ & $14(58)$ & $3(60)$ \\
\hline Face & $13(45)$ & $11(46)$ & $2(40)$ & $13(54)$ & $0(0)$ \\
\hline Head & $12(41)$ & $11(46)$ & $1(20)$ & $12(50)$ & $0(0)$ \\
\hline Thorax & $10(34)$ & $6(25)$ & $4(80)$ & $7(29)$ & $3(60)$ \\
\hline Lower limb & $6(21)$ & $6(25)$ & $0(0)$ & $5(21)$ & $1(20)$ \\
\hline Pelvis & $4(14)$ & $4(17)$ & $0(0)$ & $3(13)$ & $1(20)$ \\
\hline Neck & $4(14)$ & $3(13)$ & $1(20)$ & $3(13)$ & $1(20)$ \\
\hline Back & $4(14)$ & $3(13)$ & $1(20)$ & $3(13)$ & $1(20)$ \\
\hline Abdomen & $3(10)$ & $2(8)$ & $1(20)$ & $1(4)$ & $2(40)$ \\
\hline \multicolumn{6}{|l|}{ Type of injury (\%) } \\
\hline Wounds & $16(55)$ & $11(46)$ & $5(100)$ & $14(58)$ & $2(40)$ \\
\hline Bruises & $14(48)$ & $12(50)$ & $2(40)$ & $14(58)$ & $0(0)$ \\
\hline Fractures & $12(41)$ & $12(50)$ & $0(0)$ & $10(42)$ & $2(40)$ \\
\hline Arterial injury & $1(3)$ & $1(4)$ & $0(0)$ & $1(4)$ & $0(0)$ \\
\hline Peripheral neural injury & $3(10)$ & $2(8)$ & $1(20)$ & $3(13)$ & $0(0)$ \\
\hline Tendon injury & $3(10)$ & $1(4)$ & $2(40)$ & $3(13)$ & $0(0)$ \\
\hline Intracranial injury & $7(24)$ & $7(29)$ & $0(0)$ & $7(29)$ & $0(0)$ \\
\hline Abdominal injury & $2(7)$ & $1(4)$ & $1(20)$ & $0(0)$ & $2(40)$ \\
\hline Retroperitoneal injury & $2(7)$ & $1(4)$ & $1(20)$ & $0(0)$ & $2(40)$ \\
\hline Thoracic injury & $2(7)$ & $0(0)$ & $2(40)$ & $1(4)$ & $1(20)$ \\
\hline \multicolumn{6}{|c|}{ Total number of injuries recorded } \\
\hline Fractures & 18 & 18 & 0 & 15 & 3 \\
\hline Facial bones & 7 & 7 & 0 & 7 & 0 \\
\hline Hand & 2 & 2 & 0 & 2 & 0 \\
\hline Forearm & 2 & 2 & 0 & 2 & 0 \\
\hline Thorax & 4 & 4 & 0 & 3 & 1 \\
\hline Pelvis & 2 & 2 & 0 & 1 & 1 \\
\hline Tibia & 1 & 1 & 0 & 0 & 1 \\
\hline
\end{tabular}


Table 1 continued

\begin{tabular}{llllll}
\hline & Total & Female & Male & Adults $^{\text {a }}$ & Elderly \\
\hline Wounds & 28 & 19 & 9 & 21 & 7 \\
$\quad$ Bruises & 32 & 30 & 2 & 32 & 0 \\
Hospitalization (\%) & & & & & \\
Hospitalized & $14(48)$ & $11(46)$ & $3(60)$ & $11(46)$ & $3(60)$ \\
Surgical treatment & $10(34)$ & $7(29)$ & $3(60)$ & $7(29)$ & $3(60)$ \\
ICU observation & $2(7)$ & $2(8)$ & $0(0)$ & $1(4)$ & $1(20)$ \\
Length of stay in days, median (range) & $0(0-15)$ & $0(0-15)$ & $2(0-6)$ & $0(0-8)$ & $2(0-15)$ \\
\hline
\end{tabular}

a Adults: aged between 18 and 64 years

Table 2 Injury site, injury type and treatment

\begin{tabular}{lllll}
\hline Injury site (N) & $\begin{array}{l}\text { Severity } \\
\text { AIS score } \\
\text { Median (range) }\end{array}$ & Blunt/penetrating & $\begin{array}{l}\text { Type of injury }{ }^{\mathrm{b}} \text { (superficial/fracture/ } \\
\text { internal) }\end{array}$ & $\begin{array}{l}\text { Need for surgical treatment } \\
\text { (superficial/fracture/internal) }\end{array}$ \\
\hline Head and face 16 & $1(1-4)$ & $16 / 0$ & $5 / 4 / 7$ & $1 / 1 / 0$ \\
Head 11 & $1(1-4)$ & $11 / 0$ & $3 / 0 / 7$ & $0 / 0 / 0$ \\
Face 13 & $1(1-2)$ & $13 / 0$ & $6 / 7 / 0$ & $1 / 1 / 0$ \\
Neck 4 & $1(1)$ & $0 / 4$ & $4 / 0 / 0$ & $0 / 0 / 0$ \\
Chest 9 & $2(1-5)$ & $4 / 5$ & $3 / 4 / 2$ & $0 / 0 / 2$ \\
Abdomen 3 & $3(1-3)$ & $1 / 2$ & $1 / 0 / 2$ & $0 / 0 / 2$ \\
Extremities 20 & $1(1-4)$ & $14 / 6$ & $10 / 6 / 4$ & $0 / 2 / 3$ \\
Upper 18 & $2(1-2)$ & $12 / 6$ & $10 / 4 / 4$ & $0 / 2 / 3$ \\
Lower 7 & $2(1-4)$ & $7 / 0$ & $6 / 2 / 0$ & $0 / 0 / 0$ \\
\hline
\end{tabular}

${ }^{a}$ Abbreviated Injury Scale

b The most severe injury of each patient

Table 3 Comparison of female and male IPV victims

\begin{tabular}{lclll}
\hline$N$ & Total (29) & Female (24) & Male (5) & $p$ value \\
\hline Somatic disease & 15 & 12 & 3 & 1.00 \\
Mental condition & 8 & 6 & 2 & 0.43 \\
History of substance abuse & 9 & 6 & 3 & 0.29 \\
Fractures & 12 & 12 & 0 & 0.06 \\
Intracranial injury & 7 & 7 & 0 & 0.30 \\
Hospitalized & 13 & 10 & 3 & 0.63 \\
Surgical treatment & 10 & 7 & 3 & 0.14 \\
Wounds & 16 & 11 & 5 & 0.05 \\
Bruises & 14 & 12 & 4 & 1.00 \\
Injuries to the extremities & 19 & 15 & 5 & 0.63 \\
Injuries to the head or torso & 23 & 18 & 5 & 0.55 \\
Alcohol in blood & 13 & 8 & 4 & 0.01 \\
Weapon used & 13 & 9 & & 0.14 \\
Median (IQR) & & & $3(2.0-7.5)$ & 0.38 \\
$\quad$ Number of injuries & 3 & $2.5(1.0-5.8)$ & $3(2.5-30.5)$ & 0.32 \\
$\quad$ New Injury Severity Score (NISS) & 3 & $3(1.5-5.8)$ &
\end{tabular}

Finland, with a population of roughly 1.9 million. Given that $14 \%$ of Finnish men and women currently in a relationship report experiencing IPV from their current partner and $37 \%$ of women and $20 \%$ of men report experiencing violence from a previous partner, our patient sample for this study is rather small and represents only seriously 
Table 4 Comparison by patient age

\begin{tabular}{lclll}
\hline$N$ & Total (29) & $<65$ years (24) & 65 years or older (5) & $p$ value \\
\hline Somatic disease & 15 & 10 & 5 & 0.04 \\
Mental condition & 8 & 8 & 0 & 0.28 \\
History of substance abuse & 9 & 6 & 3 & 0.29 \\
Fractures & 12 & 10 & 2 & 1.00 \\
Intracranial injury & 7 & 7 & 0 & 0.30 \\
Hospitalized & 13 & 10 & 3 & 0.63 \\
Surgical treatment & 10 & 8 & 2 & 1.00 \\
Wounds & 16 & 14 & 2 & 0.63 \\
Bruises & 14 & 14 & 0 & 0.04 \\
Injuries to the extremities & 19 & 15 & 4 & 0.63 \\
Injuries to the head or torso & 23 & 20 & 3 & 0.27 \\
Alcohol in blood & 13 & 11 & 2 & 1.00 \\
Weapon & 13 & 11 & 2 & 1.00 \\
Median (IQR) & & & $3(1.0-8.5)$ & 0.80 \\
$\quad$ Number of injuries & 3 & $2.5(1-5)$ & $4(2.5-27)$ & 0.30 \\
$\quad$ New Injury Severity Score (NISS) & 3 & $3(2-5)$ & & \\
\hline
\end{tabular}

injured IPV victims in Helsinki and the Uusimaa region [15]. While $65 \%$ of female and $6 \%$ of male homicide victims in Finland are killed by their current or a previous partner, we had no casualties among our cohort [16]. This suggests that the most severely injured IPV victims were not included in our study and speculatively they either died at the scene or failed to report the perpetrator upon admission.

The absence of gunshot wounds in our cohort is typical for Finland [17]. In several other countries including the United States, firearms represent the most commonly used weapon in homicides, while a Portuguese study found that firearms most commonly cause IPV fatalities [18, 19]. In Finland, however, firearm-related violence is rare; homicides occur in $40 \%$ of cases through the use of sharp instruments, and more often when the perpetrator is female $[16,17]$.

In addition to the heterogeneity of IPV victims, one of the most remarkable findings from our study included the wide spectrum of the types and locations of injuries documented. Previous studies on IPV-related injuries focused on determining injury patterns to better identify IPV victims [20]. Facial and upper limb injuries on young female trauma patients were previously identified as the most likely signs of IPV [20]. Using this criteria would have eliminated the majority of our sample. Although a high prevalence of IPV exists in traumatology, physicians tend to grossly underestimate it among their patients [21]. Screening for IPV can more easily occur in clinical settings through directly questioning patients, which patients likely expect from physicians [22, 23]. We assert that the injury mechanism should be clearly defined for all trauma patients.
Most previous studies excluded male victims, and IPV is often referred to singularly as violence against women $[1,24]$. However, recent studies established that women and men are equally likely to experience IPV [3, 24]. In Finland, an intimate partner was the victim in $34 \%$ of the homicides committed by women, with problems in the relationship identified as the most common motive for such crimes [16].

Scholars generally consider IPV among men as less severe than IPV against women, whereby the common difference in physical strength between women and men is thought to result in no severe IPV-related injuries to male victims [24]. A Portuguese study found only minor injuries, such as bruises and abrasions on male victims, and sharp weapons were present in only $2.8 \%$ of cases, while an Austrian Emergency Department-based study found no male victims of IPV at all [25, 26]. In the United States, female IPV victims were two times more likely to experience abuse with a knife or a gun compared with male victims [27].

Contrary to previous studies, $17 \%$ of our sample was male, $40 \%$ of whom presented with an NISS over 15 indicating a severe trauma. We found no statistical difference between the number of injuries or NISS comparing male and female victims. More notably, the patient with the highest NISS in our study was male and the majority $(80 \%)$ of male victims in this study were stabbed. All male victims in our study were intoxicated upon admission. Since so little is known about IPV against men, we cannot state definitively if alcohol intoxication represents a major risk factor for IPV against men or if men only self-report IPV when highly intoxicated. Our sample was too small to make definitive conclusions about IPV against men as a 
phenomenon, although it is evident that severe IPV affects men as well as women.

Studies on IPV typically focus on young female trauma patients, with only a few studies focusing on elderly IPV victims [6]. In the United States, the majority of IPV victims first experienced IPV before the age of 25 years [27]. Still, nearly $20 \%$ of our cohort were 65 years or older, two of whom reported a past history of IPV. The median NISS for this group stood at 4 , which was higher than the median NISS for the other subgroups of this study. The highest NISS measured for two elderly patients reached as high as 27 .

Our study has several strengths. First, we included both men and women in this study. All patients were examined by a physician, and injury reports relied on physical examination and the victim's own report. No previous studies exist which present the severity of IPV-related injuries combined with NISS. Furthermore, the ABM form used in Töölö Hospital helped us gather detailed information on the injuries and circumstances.

Our study also carries several limitations. First, our cohort was relatively small, including only 29 patients, leading to less statistical power for subgroup comparisons. Our study only evaluated clinical files, without directly contacting patients. Thus, some important data may be missing. For instance, no reliable record of the injury mechanism was kept in either hospital. No screening for IPV was performed in either hospital and, considering the previous epidemiological studies, our cohort probably seriously underestimates the number of IPV victims treated during the study period [12]. Despite hospital protocol, the ABM form was only used for ten patients, while two additional patients previously filled in the ABM form when receiving treatment at the referring primary health care unit. At Meilahti Hospital, we reviewed all admitted injured patient files. Most victims of violence listed the perpetrator as unknown or unreported, cases which we excluded from our analysis. Since the ABM form is not used at Meilahti Hospital, no routine protocol exists allowing health care workers to ask about the patient's relationship to the perpetrator. Thus, we suspect that not all IPV victims treated at either hospital during the study period were included in our sample. Considering the methodology of the current study, our results most likely grossly underestimate the real number of IPV victims.

Health care professionals often tend to underestimate the incidence of IPV among their patients [12]. IPV is often considered as patients' private matter and health care professionals might even avoid asking about it [21]. Systematic screening for IPV is an effective way in identifying IPV victims in ER setting [12]. Future studies should include IPV screening to reveal the true incidence of IPV as a cause of injuries. Epidemiological study settings using data mining in the national registries would provide epidemiologic data on IPV. Our current results show that IPV leads to severe injuries not only among young and middle-aged women as previously thought, but also among men and elderly patients. Future studies should not exclude these patients.

In conclusion, half of all self-reporting IPV victims admitted to the emergency departments in this study required hospitalization or surgical treatment. IPV led to significant trauma, including potentially life-threatening injuries, to both female and male patients across all age groups. The precise documentation of injuries is important, not only for treatment and diagnosis but also for patients' legal protections. The spectrum of injury types and locations in our study was wide, with patients typically presenting with more than one injury. The victim's relationship to the abuser should be documented for both sexes, and IPV should be kept in mind among both female and male IPV patients across all age groups.

\section{Compliance with ethical standards}

The specific national laws were observed and an approval by an ethics committee was not required as the patients were not contacted and their treatment was not affected by the study.

Conflict of interest Elisa Hackenberg, Ville Sallinen, Virve Koljonen and Lauri Handolin declare that they have no conflict of interest.

\section{References}

1. Krug E. World report on violence and health. Geneva: World Health Organization; 2002.

2. Kjaerum M. Prevalence of physical and sexual violence. In: Violence against women: an EU-wide survey. Europe: European Union Agency for Fundamental Rights; 2014.

3. Black MC, Basile KC, Breiding MJ, et al. The national intimate partner and sexual violence survey (NISVS): 2010 summary report. 2011.

4. Dannenberg AL, Baker SP, Li G. Intentional and unintentional injuries in women. An overview. Ann Epidemiol. 1994;4(2):1339. doi:10.1016/1047-2797(94)90059-0.

5. Brown J. Male perpetrators, the gender symmetry debate, and the rejection-abuse cycle: Implications for treatment. Am J Mens Health. 2012;6(4):331-43. doi:10.1177/1557988312439404s.

6. Band-Winterstein T, Eisikovits Z. "Aging out" of violence: The multiple faces of intimate violence over the life span. Qual Health Res. 2009;19(2):164-80. doi:10.1177/1049732308329305.

7. Stark E, Flitcraft A. Women at risk: domestic violence and women's health. Thousand Oaks: Sage; 1996.

8. Max W, Rice DP, Finkelstein E, Bardwell RA, Leadbetter S. The economic toll of intimate partner violence against women in the united states. Violence Vict. 2004;19(3):259-72.

9. Wisner CL, Gilmer TP, Saltzman LE, Zink TM. Intimate partner violence against women: do victims cost health plans more? J Fam Pract. 1999;48(6):439-43.

10. Stockl H, Devries K, Rotstein A, et al. The global prevalence of intimate partner homicide: a systematic review. Lancet. 2013;382(9895):859-65. doi:10.1016/S0140-6736(13)61030-2. 
11. Campbell JC. Health consequences of intimate partner violence. Lancet. 2002;359(9314):1331-6. pii:S0140-6736(02)08336-8.

12. PRAISE Investigators, Sprague $S$, Bhandari $M$, et al. Prevalence of abuse and intimate partner violence surgical evaluation (PRAISE) in orthopaedic fracture clinics: a multinational prevalence study. Lancet. 2013;382(9895):866-876. doi:10.1016/ S0140-6736(13)61205-2.

13. Osler T, Baker SP, Long W. A modification of the injury severity score that both improves accuracy and simplifies scoring. $\mathrm{J}$ Trauma. 1997;43(6):922-5 discussion 925-6.

14. Noponen T. Scars of ordinary life: Abuse and Body Map form as a tool in work against violence ("Arjen arvet: Pahoinpitelyja kehokarttalomake väkivaltatyön välineenä”). Tampere: Police University College; 2007.

15. Heiskanen M, Ruuskanen E. Volence against men in Finland (Tuhansien iskujen maa. Miesten kokema väkivalta Suomessa.) European institute for crime prevention and control, affiliated with the United Nations. 2010.

16. Lehti M. Homicides, homicide offenders and victims in Finland 2014. (Henkirikoskatsaus.) The National Research Institute of Legal Policy. 2014.

17. Wahlsten P, Koiranen V, Saukko P. Survey of medico-legal investigation of homicides in the city of Turku, Finland. J Forensic Leg Med. 2007;14(5):243-52. pii:S1353-1131(06)00179-9.

18. Pereira AR, Vieira DN, Magalhaes T. Fatal intimate partner violence against women in portugal: a forensic medical national study. J Forensic Leg Med. 2013;20(8):1099-107. doi:10.1016/j. jflm.2013.09.015.

19. Parks SE, Johnson LL, McDaniel DD, Gladden M. Centers for Disease Control and Prevention (CDC). Surveillance for violent deaths - national violent death reporting system, 16 states, 2010. MMWR Surveill Summ. 2014;63(1):1-33. pii:ss6301a1.
20. Wu V, Huff $\mathrm{H}$, Bhandari M. Pattern of physical injury associated with intimate partner violence in women presenting to the emergency department: a systematic review and meta-analysis. Trauma Violence Abuse. 2010;11(2):71-82. doi: $10.1177 / 1524838010367503$.

21. Bhandari M, Sprague S, Tornetta P, 3rd, et al. (Mis)perceptions about intimate partner violence in women presenting for orthopaedic care: a survey of canadian orthopaedic surgeons. J Bone Joint Surg Am. 2008;90(7):1590-1597. doi:10.2106/ JBJS.G.01188.

22. Wester W, Wong SL, Lagro-Janssen AL. What do abused women expect from their family physicians? A qualitative study among women in shelter homes. Women Health. 2007;45(1):105-19. doi:10.1300/J013v45n01_07.

23. Todahl J, Walters E. Universal screening for intimate partner violence: a systematic review. J Marital Fam Ther. 2011;37(3):35569. doi:10.1111/j.1752-0606.2009.00179.x.

24. Straus MA. Future research on gender symmetry in physical assaults on partners. Violence Against Women. 2006;12(11):1086-97.

25. Carmo R, Grams A, Magalhaes T. Men as victims of intimate partner violence. J Forensic Leg Med. 2011;18(8):355-9. doi:10.1016/j.jflm.2011.07.006.

26. Burkert NT, Rasky E, Freidl W, et al. Female and male victims of violence in an urban emergency room-prevalence, sociodemographic characteristics, alcohol intake, and injury patterns. Wien Klin Wochenschr. 2013;125(5-6):134-8. doi:10.1007/ s00508-013-0329-z.

27. Breiding MJ, Smith SG, Basile KC, Walters ML, Chen J, Merrick MT. Prevalence and characteristics of sexual violence, stalking, and intimate partner violence victimization-national intimate partner and sexual violence survey, united states, 2011. MMWR Surveill Summ. 2014;63(8):1-18. pii:ss6308a1. 